\title{
Surgical considerations in the treatment of acute acquired ventricular septal defect
}

\author{
LORENZO GONZALEZ-LAVIN ${ }^{1}$ and ROSTIK ZAJTCHUK \\ Department of Surgery, Section of Thoracic and Cardiovascular Surgery, University of Chicago, \\ Division of Biological Sciences and Pritzker School of Medicine, Chicago, Illinois
}

In the light of our experience and that of others (Oldham et al., 1969 ; Iben, Pupello, Stinson, and Shumway, 1969), early surgical closure of acquired ventricular septal defect is advocated. Two successful cases are presented, one after myocardial infarction and one after penetrating trauma to the heart. Description of the present method of repair is presented. Two prosthetic patches are interposed in the closure of the defect. The advantages of this technique are $(a)$ the key sutures are placed through healthy tissue and are anchored by the two patches, and $(b)$ an additional suture line along the free edge of the right ventricular patch ensures a complete closure.

Acquired perforations of the ventricular septum occur as a result of myocardial infarction or trauma to the heart (Rubenstein and Levinson, 1961; Lee, Cardon, and Slodki, 1962; Lundberg and Söderström, 1962; Beall, Hamit, Cooley, and DeBakey, 1965). The left-to-right shunt following perforation will produce acute haemodynamic disturbances that aggravate the already impaired myocardial function.

The definitive treatment of an acquired ventricular septal defect is surgical closure (Schickman, Fields, and Pearce, 1959; Boicourt et al., 1962; Payne, Hunt, and Kirklin, 1963). It has been said that the optimum time for repair of these lesions is six to eight weeks after perforation when the edges of the defect are well delineated and enough fibrous tissue has developed to facilitate a secure closure (Dobell, Scott, Cronin, and Reid, 1962 ; Collis, Mackinnon, Raison, and Whittaker, 1962; Davison et al., 1964; Allen and Woodwark, 1966). In an important number of cases, however, the cardiovascular function and general condition of the patient deteriorate rapidly despite vigorous treatment. Several studies have shown that survival without operation is unlikely (Oyamada and Queen, 1961). Surgery, then, should be undertaken as soon as the patient develops unrelenting failure regardless of the time of injury or perforation.

We have recently operated successfully on two patients using a modified surgical technique with

1Reprint requests to: Lorenzo Gonzalez-Lavin, M.D., Department of Surgery, National Heart Hospital, Westmoreland Sireet, London W.1 excellent results. The experience gained in these cases is the basis of this report.

\section{CLINICAL MATERIAL}

CASE 1 A 72-year-old Negro was brought to the emergency room complaining of severe chest pain, shortness of breath, and weakness. On admission he $\vec{\overrightarrow{ }}$ was diaphoretic with a blood pressure of $80 / 60 \mathrm{mmHg} 3$ and a pulse of 130 per minute. He had an elevated jugular venous pressure and a positive hepatojugular reflux.

A systolic thrill was palpable at the left sternal edge. On auscultation there was a pansystolic murmur grade II/IV. The liver was enlarged and there were bilateral basal rales. A chest radiograph confirmed an overall enlargement of the heart and marked pulmonary congestion.

An electrocardiogram showed a recent transmural inferior myocardial infarction.

Four days after admission the patient developed $D$ systolic pulsation of the neck veins and the systolic murmur at the left sternal edge became more prominent (III/IV). The diagnosis of ventricular septal $\odot$ defect secondary to myocardial infarction was made N and was confirmed by cardiac catheterization.

In spite of vigorous medical treatment the patient's condition did not improve and he was referred to surgery the third week after myocardial infarction.

At surgery a large ventricular septal defect was $\mathbb{\mathscr { D }}$ found at the muscular portion of the ventricular sep-? tum near the apex. It measured $4 \times 5 \mathrm{~cm}$ in diameter. $T$ The edges of the defect were ragged and irregular with some necrotic tissue in the lower part. The defect $\stackrel{\mathbb{D}}{\Omega}$ was closed by interposing two prosthetic patches. 
The postoperative course was initially complicated by a haemorrhagic diathesis necessitating re-exploration. Five months postoperatively, however, he is doing very well and has returned to normal activities. A postoperative cineangiogram showed complete closure of the ventricular septal defect (Fig. 1).

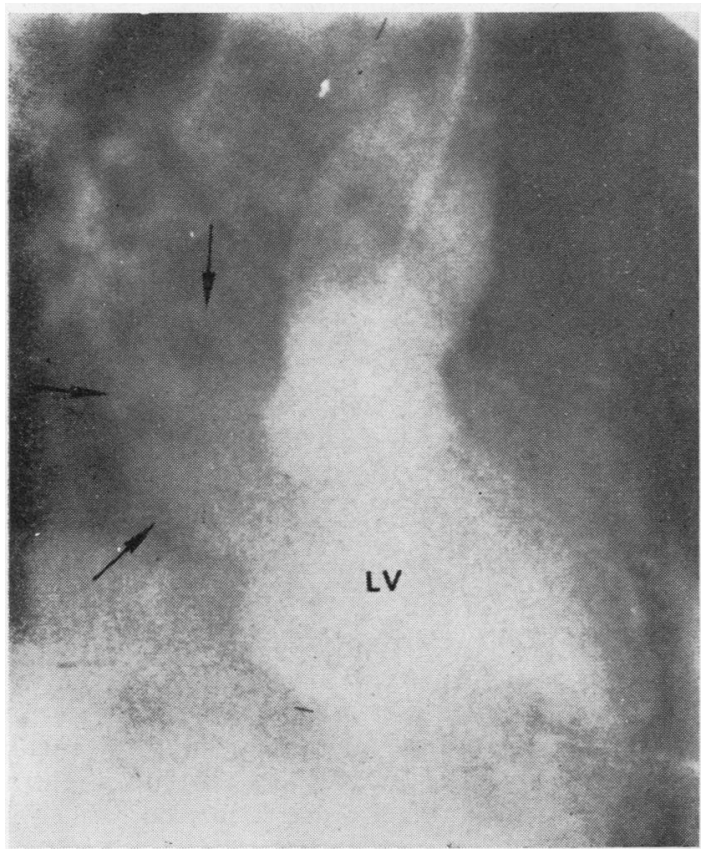

FIG. 1. Postoperative cineangiocardiogram. There is no evidence of a left-to-right shunt at the ventricular level. A grade 1 mitral insufficiency is shown with faint filling of the left atrium (arrows).

CASE 2 A 16-year-old Negro boy was admitted to the hospital as an emergency in April 1970 with a stab wound of the precordium. On admission he was in shock with a blood pressure of $80 / 60 \mathrm{mmHg}$, pulse 120 per minute, and a central venous pressure of $25 \mathrm{~cm} \mathrm{H}_{2} \mathrm{O}$. The wound was through the sixth intercostal space near the left sternal border. Heart sounds were distant and no thrill or murmurs were detected. After an initial pericardiocentesis the diagnosis of cardiac tamponade was made and, because of further deterioration of the patient's condition, he underwent an immediate exploratory thoracotomy.

Through a midline sternotomy the pericardial sac was opened and found to contain $500 \mathrm{ml}$ of blood. A 3-cm laceration was found on the anterior wall of the right ventricle near the anterior descending coronary artery. There was bright red blood coming through the laceration. The bleeding from the right ventricle was controlled with multiple interrupted sutures. A systolic thrill then was present on the pulmonary artery and right ventricle, with progressive dilatation of this chamber and deterioration of the patient's condition. The patient was placed on cardiopulmonary bypass and the wound of the right ventricle was re-opened. Exploration revealed a large septal defect located in the muscular portion of the septum that measured $2 \times 3 \mathrm{~cm}$ with ragged edges which were infiltrated by a large haematoma. In addition, a papillary muscle was found to be severed. After re-attaching the papillary muscle, the defect was closed by interposing two prosthetic patches of Dacron using two suture lines. The heart took over the load of the circulation without difficulty at the termination of cardiopulmonary bypass.

The postoperative course was uneventful. When last seen four months after surgery, the patient was asymptomatic. Physical examination revealed normal heart sounds and he has returned to his normal activities.

\section{SURGICAL TECHNIQUE}

The heart is exposed through a midline sternotomy and, after heparinization, the ascending aorta and both venae cavae are cannulated. Normothermic high-flow cardiopulmonary bypass is established using a bubble oxygenator and haemodilution. The aorta is cross-clamped and a vent is placed in the left ventricle. Anoxic arrest up to 45 minutes is allowed and generally is well tolerated. The ventricular septal defect is exposed through a right ventriculotomy (Fig. 2); the incision is made over the

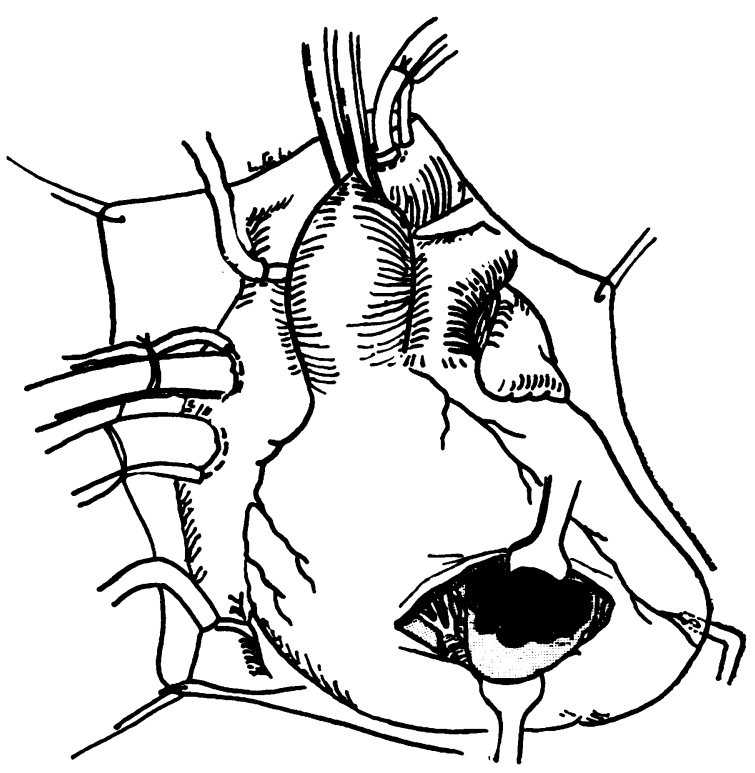

FIG. 2. Operative approach. 


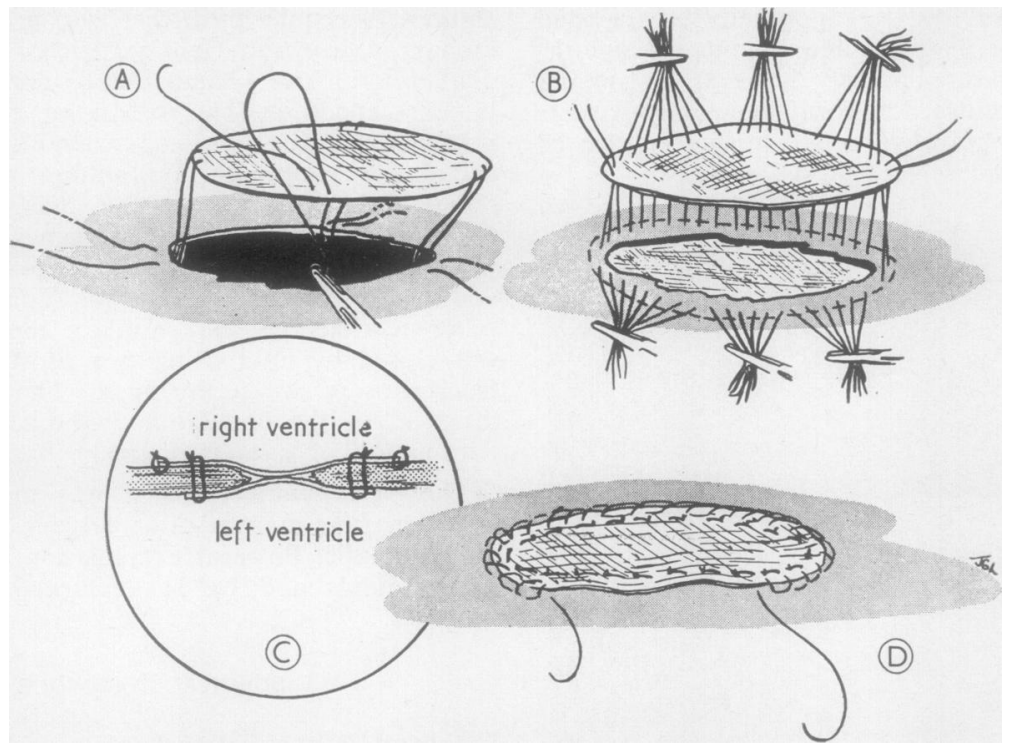

FIG. 3. Technique of closure of an acquired ventricular septal defect. See text.

area of maximum thrill. Division of some trabeculae is necessary to expose the true edges of the defect.

Closure of the communication is performed by interposing two prosthetic patches of Dacron. The first patch is tailored $1 \mathrm{~cm}$ in excess of the circumference of the defect. Multiple interrupted mattress sutures are passed from the patch into the left ventricular aspect of the septum approximately 1.5 $\mathrm{cm}$ from the edge of the defect, through the entire thickness of the septum and into the right ventricle (Fig. 3A). With these sutures under tension, the patch is slid down into the left ventricle obliterating the defect from the left side. A second patch $2 \mathrm{~cm}$ larger than the circumference of the defect is prepared. The previously placed sutures are then passed through the second patch (Fig. 3B) and are tied down after sliding the patch down against the right ventricular aspect of the septum. In this manner the defect is doubly obliterated with one patch on each side of the ventricular septum (Fig. 3C). To avoid any residual leaks, the free edge of the second patch in the right ventricle is then sutured to the septum with a running stitch (Fig. 3D).

After closing the right ventricular incision, air is evacuated from the heart. When cardiac performance is adequate, cardiopulmonary bypass is discontinued. Atrial and ventricular pacing wires are placed and the chest is closed in layers.

\section{DISCUSSION}

Coronary artery disease is nowadays a prevalent entity, and complications of acute myocardial infarction are being reported with increasing frequency (Edmondson and Hoxie, 1942 ; Myers,
Klein, and Hiratzka, 1949 ; Proudfit, Tapia, Mc-Cormack, and Effler, 1959 ; Holloway, Whalen, and McIntosh, 1965 ; Campion et al., 1968). Rupture of the ventricular septum is one of theo most serious, and life expectancy following un-0ूँ treated rupture of the septum is short (Oyamada $\mathcal{D}$ and Queen, 1961). Since the advent of extra- $\overrightarrow{0}$ corporeal circulation, however, this complication 3 is amenable to surgical correction (Cooley, Belmonte, Zeis, and Schnur, 1957).

The results of early surgical repair appear to be approximately equal to those of late repairo (Oldham et al., 1969 ; Iben, Pupello, Stinson, andx Shumway, 1969). Early surgery will undoubtedlyo benefit the group of patients who deteriorate rapidly despite vigorous medical treatment. Theo main problem in this group, as shown by earlier experience (Barnard and Kennedy, 1965 ; Grismero et al., 1966), is that placing and tying sutures directly against friable muscle produces immedi을 ate tissue disruption, resulting in a high incidencen of suture line leaks. The presented method of repair, however, can be applied at any stage follow ing perforation of the septum.

The complex juxtaposition of the differene chambers of the heart creates the possibility of a large variety of traumatic fistulae after pene trating wounds (Summerall, Lee, and Boone? 1965). Ventricular septal defect and aorta to righto ventricular communication are among those mos? frequently reported (King and Shumacker, 1958 Morris, Foster, Dunn, and Cooley, $1958 \stackrel{\mathbb{Q}}{\circ}$ 
Summerall et al., 1965 ; Rogers, Chesler, and du Plessis, 1969). Early exploration through a midline sternotomy has been our routine approach for penetrating injuries into the precordial area. In addition to being a fast method of opening the pericardial cavity, it gives excellent exposure to the great vessels and the cardiac chambers. After the bleeding has been controlled, inspection and careful palpation of the heart is mandatory. When a ventricular septal defect complicates the injury, the right ventricular cavity will become progressively larger and a systolic thrill will be present. A useful manœuvre to confirm the diagnosis is palpation of the ventricular septum after introducing the index finger through the tricuspid valve via the right atrium. A definite rush of blood under higher pressure into the right ventricle can be felt with each cardiac contraction. As soon as the diagnosis is verified, preparations for cardiopulmonary bypass are made, and exploration and closure of the defect are performed.

The described method of repair has proved to be very satisfactory in both situations of acquired ventricular septal defect where the edges of the defect are irregular, ragged, with some necrotic tissue or infiltration of blood. The key sutures are placed through healthy tissue and are anchored by the two patches. The additional suture line along the free edge of the right ventricular patch ensures a complete closure.

Acknowledgements to Leon Resnekov, M.D., for referring the first patient to us, to Klaus Ranniger, M.D., for the angiographic studies, and to Vicki Adler and Susan Thomas for technical assistance in the preparation of this paper.

\section{REFERENCES}

Allen, P., and Woodwark, G. (1966). Surgical management of postinfarction ventricular septal defects. $J$. thorac. cardiovasc. Surg., 51, 346.

Barnard, P. M., and Kennedy, J. H. (1965). Postinfarction ventricular septal defect. Circulation, 32, 76.

Beall, A. C. Jr., Hamit, H. F., Cooley, D. A., and DeBakey, M. E. (1965). Surgical management of traumatic intracardiac lesions. J. Trauma, 5, 133.

Boicourt, O. W., Ritzmann, L. W., Chase, J. D., Starr, A., and McCord, C. W. (1962). Rupture of the infarcted interventricular septum: Surgical repair with survival. Circulation, 26, 1321.

Campion, B. C., Harrison, C. E. Jr., Giuliani, E. R., Ellis, F. H. Jr., and Schattenberg, T. T. (1968). Ventricular septal defect after myocardial infarction. Ann. intern. Med., 68, 1152.

Collis, J. L., Mackinnon, J., Raison, J. C. A., and Whittaker, S. R. F. (1962). Repair of acquired interventricular septal defect following myocardial infarction. Lancet, 2 ,
Cooley, D. A., Belmonte, B. A., Zeis, L. B., and Schnur, S. (1957). Surgical repair of ruptured interventricular septum following acute myocardial infarction. Surgery, 41, 930.

Davison, T., Degenshein, G. A., Yuceoglu, Y. Z., Reyes, A. L. Jr., Levowitz, B., Dresdale, D. T., and Kantrowitz, A. (1964). Repair of ventricular septal defect following myocardial infarction. Ann. Surg., 160, 33.

Dobell, A. R. C., Scott, H. J., Cronin, R. F. P., and Reid, E. A. S. (1962). Surgical closure of interventricular septal perforation complicating myocardial infarction. $J$. thorac. cardiovasc. Surg., 43, 802.

Edmondson, H. A., and Hoxie, H. J. (1942). Hypertension and cardiac rupture: A clinical and pathologic study of seventy-two cases, in thirteen of which rupture of the interventricular septum occurred. Amer. Heart. J., 24, 719.

Grismer, J. T., Raab, D. E., Berman, D. A., Berman, R., and Hill, E. (1966). Successful repair of a ruptured ventricular septum complicating a recent myocardial infarction. Amer. J. Cardiol., 18, 120.

Holloway, D. H. Jr., Whalen, R. E., and McIntosh, H. D. (1965). Systolic murmur developing after myocardial ischemia or infarction: Differential diagnosis. J. Amer. med. Ass., 191, 888.

Iben, A. B., Pupello, D. F., Stinson, E. B., and Shumway, N. E. (1969). Surgical treatment of postinfarction ventricular septal defects. Ann. thorac. Surg., 8, 252.

King, H., and Shumacker, H. B. (1958). Surgical repair of a traumatic aortic-right ventricular fistula. J. thorac. Surg., 35, 734.

Lee, W. Y., Cardon, L., and Slodki, S. J. (1962). Perforation of infarcted interventricular septum: Report of a case with prolonged survival, diagnosed ante mortem by cardiac catheterization, and review of the literature. Arch. intern. Med., 109, 731.

Lundberg, S., and Söderström, J. (1962). Perforation of the interventricular septum in myocardial infarction. A study based upon an autopsy material. Acta med. scand., $172,413$.

Morris, G. C. Jr., Foster, R. P., Dunn, J. R., and Cooley, D. A. (1958). Traumatic aortico-ventricular fistula: Report of two cases successfully repaired. Amer. Surgn., 24, 883.

Myers, G. B., Klein, H. A., and Hiratzka, T. (1949). Correlation of electrocardiographic and pathologic findings in infarction of the interventricular septum and right ventricle. Amer. Heart J., 37, 720.

Oldham, H. N. Jr., Scott, S. M., Dart, C. H. Jr., Fish, R. G., Claxton, C. P., Dillon, M. L. Jr., and Sabiston, D. C. Jr. (1969). Surgical correction of ventricular septal defect following acute myocardial infarction. Ann. thorac. Surg., 7, 193.

Oyamada, A., and Queen, F. B. (1961). Spontaneous rupture of the interventricular septum following acute myocardial infarction with some clinicopathological observations on survival in five cases. Presented at Pan Pacific Pathology Congress. Tripler U.S. Army Hospital, Honolulu, Hawaii, October 12.

Payne, W. S., Hunt, J. C., and Kirklin, J. W. (1963). Surgical repair of ventricular septal defect due to myocardial infarction: report of a case. J. Amer. med. Ass., 183, 603.

Proudfit, W. L., Tapia, F. A., McCormack, L. J., and Effler, D. B. (1959). Rupture of the ventricular myocardium and perforation of the interventricular septum complicating acute myocardial infarction. Circulation, 20, 128. 
Rogers, M. A., Chesler, E., and Du Plessis, L. (1969). Surgical management of traumatic cardiac fistulae. Thorax, 24, 543.

Rubenstein, P., and Levinson, D. C. (1961). Acquired interventricular septal defects due to myocardial infarction and nonpenetrating trauma to the chest. Amer.J. Cardiol., 7, 277.
Schickman, M. D., Fields, J., and Pearce, M. L. (1959). Repair of ruptured interventricular septum complicating acute myocardial infarction. Arch. intern. Med., 103, 140.

Summerall, C. P. 3rd., Lee, W. H. Jr., and Boone, J. A. $\stackrel{\mathbb{\Phi}}{\Omega}$ (1965). Intracardiac shunts after penetrating wounds of the heart. New Engl. J. Med., 272, 240. 